\title{
Women and Crime in Central Business District Area
}

\author{
Rohana Sham, Norhayati Omar, Dia Widyawati Amat \\ Faculty of Business Management, \\ Universiti Teknologi MARA Johor, KM12 Jalan Muar, 85000 Segamat, Johor, Malaysia \\ rohana320@johor.uitm.edu.my
}

\begin{abstract}
Crime in the central business district has gain momentum over several years. With the increasing of a non index crime in Malaysia, it has also indirectly increase the chances of becoming a crime victim among women. Thus, this study intended to examine the exact crime incident area in the city centre that will affect the working women who depend on stage bus to commute. Result shows that most crime occur while walking and waiting at the bus stop. A high level of unsafe were spotted, when they rated a higher dissatisfaction against attributes like comfortable, security and information of the bus.

Keywords: Woman travellers; Crime area ;Central Business District; Level of safety ,

eISSN 2398-4295 (C) 2018. The Authors. Published for AMER ABRA cE-Bs by e-International Publishing House, Ltd., UK. This is an open-access article under the CC BY-NC-ND license (http://creativecommons.org/licenses/by$n c-n d / 4.0 /$ ). Peer-review under responsibility of AMER (Association of Malaysian Environment-Behaviour Researchers), ABRA (Association of Behavioural Researchers on Asians) and CE-Bs (Centre for EnvironmentBehaviour Studies), Faculty of Architecture, Planning \& Surveying, Universiti Teknologi MARA, Malaysia.

DOI: http://dx.doi.org/10.21834/ajbes.v3i9.74
\end{abstract}




\subsection{Introduction}

Record in the increase crime activities in urban area in Malaysia has been observed. In relation to this, women have been targeted more by crime offenders since years ago compared to men, and this heightens women's unsafe feeling. A study by Siti and Aldrin in 2011 had further indicated that the correlation between Fear of Crime (FOC) and gender is significant.

Even though the crime itself does not directly demonstrate that it is a transport-related crime, traditionally a high crime occurrence subscribes to the belief that the higher the crime rate in a particular area, the higher would be the chances of becoming a victim of crime in that particular area. This will in turn create a higher feeling of unsafe among travellers especially in urban areas where the trip attraction is extraordinarily high. In spite of considerable media attention on the reporting of serious crime on women, the exact crime area in the city centre for woman travellers remains an open question. In the meantime, in most urban areas in Malaysia, especially an island like Penang, the glowing mass public transport is more likely to be public bus system. The public bus can be considered as the lifeblood of the state economy as most urban dwellers especially women depend on it to commute, for various purposes. Problems arise when poor public transport provision like bus service and its infrastructure are not being well taken care of. Bad infrastructure especially walkways to and from the stop, poor design and maintenance of bus stop and busses, inadequate security measures throughout the entire journey have also risk women's movement into the risk of crime victimization. In addition to that, for most women living in an urban area, the reality of fear of assault, attack, harassment and verbal abuse is one of the major influences on their travel decision, especially at night (Howie 2000).

So far, there is no sufficient information regarding this type of problem faced by woman travellers in Penang Island. Therefore, this study aimed to examine critically the historical factors that contributed towards women travelling safety issues. Among the objectives of the study is to determine the central hot spot areas for crime incidence among woman travellers.

\subsection{Literature Review}

Over the years, progress has been made to identify the factors affecting woman travelling safety because women are considered as a group of people who will face the highest risk of victimization. As a result, Hanlon (1995) contended that their access to safe and vigorous public transportation resources is essential especially to those living in an urban area. A recent study by Rohana, Syed, Mashita and Suhana (2012) had also indicated that poor public transport supply had also contributed to the problem of crime against women and thus increase their level of fear while travelling.

It has conclusively been shown that the safety issues surrounding the bus services are a serious matter that needs urgent attention especially when services in metropolitan area are concerned. This is because Grieco, Pickup and Whipp (1989) contended that besides having to cope with a higher crime rate in an urban area, it is believed that for a public transport to remain competitive in the transport industry, the needs of the passengers especially the dominant users like women must first be addressed. 
Nasar and Fisher (1993) had reported that designers such as architects and planners often focus on reducing crime by engaging the physical environmental strategy. According to them, the approach is based on the understanding that the physical environment can be modified through planning and design in order to reduce the opportunities for crime. On the other hand, Lamya and Ali in 2006 discovered that elements such as physical layout, housing typology and the expectations of the surrounding environment directly influence crime. A study in 2007 by Anastasia and John concluded that poor physical environmental design contributes towards higher crime. A study done by Villarreal and Silva in 2006 had further concluded that a good relationship between residential group members is vital in ensuring crime rate reduction. Their study focused on the relationship among the community members as crime reduction tools.

The following diagram indicates the grounded theory of crime structure and crime prevention through environmental design used in the study to further highlight the issues of hot spot crime occurrence in urban areas for woman travellers.

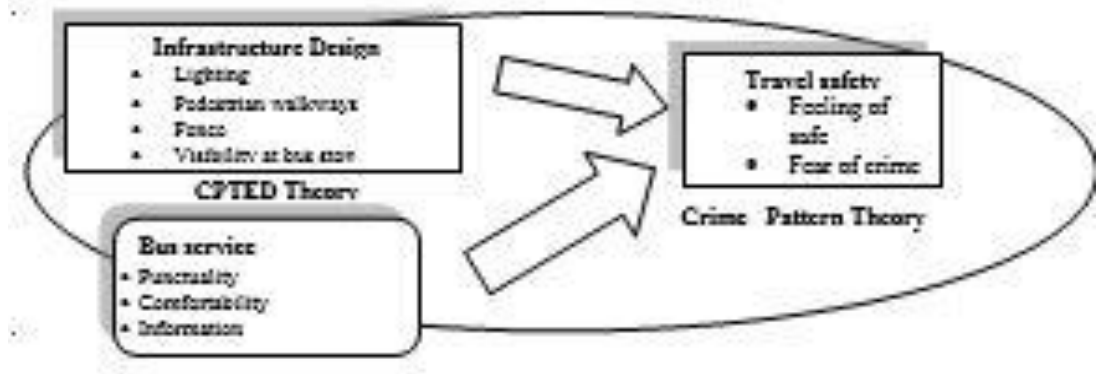

Figure 1. CPTED Theory and Crime Pattern Theory

This study focuses on the infrastructure plan as well as the bus service to further examine on the travel safety issues and thus highlighting the perfect crime incident point during the entire journey from point of origin to destination

\subsection{Crime Area}

In 2002, Levinson continued to show that women are more susceptible of being the crime victims generally snatch robbery while walking or waiting at the bus stop. The situation would be worsened if they have to wait for a longer time at the bus stop or walk for a longer distance to the bus stop. In the same year, a recent research conducted by Crime Concern (2002) in Buckinghamshire, identified that fears for personal safety at unlit bus stop was a serious impediment to use the public transport facilities and services.

Over the past century in Penang Island itself, there has been a dramatic increase in the statistics of crime being recorded. Although the reporting of crime in Penang Island does not indicate that it is a crime related to transportation and women travelling by bus services, a 
report from the Criminal Department Unit (2005) confirmed that most of the crime happen to be at the limits of public transport facilities amenities such as along the main road, and while walking and waiting at the bus stop. Even though, the reporting of crime in a bus was never given any consideration, the phenomenon is believed to be quite high particularly during peak hours of the bus usage.

The following section gives comprehensive analysis on data collection process, analysis of the findings, conclusion and recommendations.

\subsection{Methodology}

Data set was conducted in three main metropolitan areas in Penang Island itself specifically Pulau Tikus, Jelutong and Ayer Itam. Unit of analysis is individual. A quota and stratified sampling method were carried out through out the survey to obtained a valid result and findings from the 3 main area selected. Only women who travel by stage bus to commute to the central business district were being surveyed. The respondents were typically asked to rate their current stage bus attributes in their area which consist of punctuality, comfortability, security, information and infrastructure design. Then, they were also asked to rate their sense of safe travelling in current situation of transport infrastructure facilities such as pedestrian walkways and bus stop design.

An inferential analysis were then carried out to look at the correlation between satisfaction level and fear of crime. Then respondent were ask to identify their crime experienced to further tap on the real point of crime along the journey for future planning.

While conducting the bus passenger survey, surveyors were located at the bus top at specific housing area (Pulau Tikus,Jelutong and Ayer Itam) in order to get the real respondents who travel by stage bus. These activities lasted for 5 hours started from early morning at $6.00 \mathrm{am}$ to $11 \mathrm{am}$ for 5 days (Monday to Friday). Saturday and Sunday were excluded because Saturday and Sunday are considered as a weekend travelling. Moreover, it is quite difficult to find those going to work on Saturday and Sunday. The primary restriction or failure of using this method is purely because of the time of answering the question. Some of the questions could not be finished by the respondents due to the unknown bus arrivals. To overcome that, surveyors were asked to go on board with the respondents in case the questionnaire was not completed. This has resulted in a new methodology and approach call in this study that is to undertake into an onboard survey where necessary.

\subsection{Findings and Discussions}

Table 1 shows general descriptive analysis for the woman bus riders being analysed in this study. The aspects being analysed include the age of respondents as well as respondents' monthly income. This information is essential as to create a real picture of our respondent background according to different metropolitan area selected.

\section{Table 1. Demographic Pattern of Women Bus Travellers}




\begin{tabular}{|c|c|}
\hline Demography Pattern & Percentage (\%) \\
\hline $\begin{aligned} & \text { Age of respondents: } \\
& \text { - } 20 \text { 's } \\
& \bullet 30 \text { 's } \\
& \text { - } 40 \text { 's } \\
& \text { - } 50 \text { 's } \\
& \text { Income: } \\
& \text { - }<\text { RM500 } \\
& \text { - } \text { RM500-RM1000 } \\
& \text { - } \text { RM1000-RM1500 } \\
& \text { - }>\text { RM1500 }\end{aligned}$ & $\begin{array}{c}24.4 \\
44.2 \\
15.6 \\
15.9 \\
\\
3 \\
73.8 \\
16.4 \\
6.7\end{array}$ \\
\hline
\end{tabular}

The distribution of the demographic pattern data among the age group consists of the majority of women in the age group of 30's (44.2\%). This was followed by women in the age group of 20's (24.4\%), women in age of 50's (15.9\%) and women in the 40's (15.6\%). Meanwhile, it was analysed that over $70 \%$ of the respondents were of those with earning income range RM500 - RM1000 per month. This shows that a majority of the woman travellers who depended on public transportation were the ones with low income. This situation indicates that it is necessary to increase the level of security in public transport services so that security issues will not be a barrier for women from lower income group to travel and improve their economic status.

The study found that, punctuality and security are the two most notable attributes indicated by most woman commuters in Penang urban areas as factors that affect their level of safety if the attributes failed to satisfy them. It was also found that woman travellers express comfortability as the feature that would affect their safe feeling the least. Results of the mean score analysis are presented in table 2.

Table 2. Mean score for factors that affect the level of safety

\begin{tabular}{c|cc}
\hline & $\begin{array}{c}\text { Mean score } \\
(1-5)^{*}\end{array}$ & Mode \\
\hline Service attribute: & 2.66 & 1 \\
- Punctuality & 3.67 & 5 \\
- Comfortability & 2.38 & 1 \\
- Security & 2.40 & 2 \\
- Information & 3.51 & 4 \\
\hline
\end{tabular}


need to control the public transport operation system especially on the basic service operation like punctuality, security, information, comfortability and infrastructure provision. Besides that, by opting comfortability as the factor that affect safety level the least while commuting by public transport, it is suggested that public bus companies should provide more effort to improve their services by prioritising punctuality, security and intelligence of services than offering comfort to the commuters.

Table 3. Mean score for level of safety that a women experience travelling on current service characteristics

\begin{tabular}{|c|c|}
\hline Service characteristics & Mean Score (the 1-7) \\
\hline $\begin{array}{l}\text { Service attribute: } \\
\text { - Waiting too long at the bus stop } \\
\text { - The bus fails to come on time } \\
\text { - Trile in the bus, } \\
\text { - Travelling with sufficient information } \\
\text { - Travelling with common facilities }\end{array}$ & $\begin{array}{l}2.12 \\
1.72 \\
3.94 \\
5.22 \\
2.36\end{array}$ \\
\hline
\end{tabular}

*1- Very unsafe

7- Very safe

Table 3 presents the mean score analysis for safety level indication while travelling using the current bus services. The results show that woman commuters indicated a higher level of unsafe when the bus fails to arrive on time (1.72) and when waiting too long at the bus stop (2.12). However, the response of feeling of safe differs for 'in the bus' (3.94) and 'travelling with ample information' (5.22) which indicates that they feel much safer in the bus and even 'safer' when they can access ample information about the services beforehand. When the respondents were asked to rate their level of safety travelling with current facilities or infrastructure design, most of them indicated higher feeling of unsafe (2.36).

The implication of the results shows that woman commuters feel much safer if they can get access to information of the bus services beforehand. Not only that, to be able to reduce the waiting time spent at a bus stop would also increase their level of safety. This will help to reduce the victimization cases.

To understand the phenomena of crime experience and crime location, the following descriptive analysis was conducted, and results are presented in Table 4. Approximately, majority of the respondents surveyed indicated that they had been both the victim and witness of crimes while travelling by bus service (80\%). Only around $20 \%$ of the total respondents for stage bus indicated 'no experience'.

In response to the location of crime, $74.2 \%$ of the respondents claimed that most crime happened 'while walking to and from stop'. Another $65.3 \%$ of the crimes reported in this survey happened 'while waiting at the bus stop'. This is then followed by a large amount of crime reported having happened while 'in the bus' $(41.6 \%)$. The least reporting crime incident was 'walking to final destination' (22\%). 
Table 4. Crime Experience

\begin{tabular}{|c|c|}
\hline Crime experience attributes & Stage Bus \%) \\
\hline Crime experience: & $10 \%$ \\
- $\quad$ Been a victim & $17.9 \%$ \\
- $\quad$ Bitness & $51.6 \%$ \\
- $\quad$ Noth victim and witness & $20(\%)$ \\
Location of the crime: & \\
- Walking to and from the bus stop & $74.2 \%$ \\
- Waiting at the bus stop & $65.3 \%$ \\
- $\quad$ In the bus & $41.6 \%$ \\
& \\
\hline
\end{tabular}

A correlation analysis was carried out among the transport service attribute and level of safety was tapped. The following results were obtained:

Table 5. Correlation Analysis on Service Attribute

\begin{tabular}{|c|c|c|}
\hline & Correlation coefficient values ( $r$ ) & Spearman $p$ values \\
\hline $\begin{array}{cl}\text { Service attribute: } \\
\text { - } & \text { Punctuality } \\
\text { - } & \text { Comfortability } \\
\text { - } & \text { Security } \\
\text { - } & \text { Information }\end{array}$ & $\begin{array}{l}.2 \\
.17 \\
.4 \\
.14\end{array}$ & $\begin{array}{l}.001^{\star *} \\
.003^{*} \\
.000^{\star *} \\
.012^{*}\end{array}$ \\
\hline
\end{tabular}

Table 5 summarizes the correlation analysis of each of the service attributes and level of safety. The results show that all service attributes significantly affect women's level of safety with attribute like punctuality and security showing a highly significant. An implication of the results indicates that control for standard operation of the bus especially on the management side or known as supply side is urgently needed as failure to perform this factor can cause a greater fear among the woman travelers especially those living in urban area who commute to work on a daily basis.

\subsection{Conclusion}

\subsection{Conclusion}

The main contribution of this research is the analysis of the relationship between public transport supply and the travelling safety issues in the central business district. The results 
show that control for public transport supply are essential in understanding the fear of crime among woman travellers who possess a unique personal travel pattern. In this investigation, the aim was to determine the exact location of crime among women commuters. Along the journey, walking to and from the bus stop were considered as a critical point where most crime happen. Second hot spot crime area is while waiting for the stage bus at the bus stop.

\subsection{Recommendations}

- Setting up guideline for standard operating of bus services in urban areas so that the amount of fear while travelling could be reduced to a minimum level.

- Proper planning of transport infrastructure that takes into account the travelling needs of women especially on the environmental surrounding the walking to and from the stop and waiting area should be implemented.

\section{Acknowledgement}

Heartfelt thanks to all family members and colleagues for the completion of this paper. Not to forget people from transport industry especially public bus transport operators who have contributed directly and indirectly. Utmost thanks also go to all woman travellers who have cooperated and given feedback during the field survey. Many thanks also go to Universiti Teknologi MARA Cawangan Johor for all the resources bestowed for this study.

\section{References}

Anastasia, L.-S. \& John, E. E. (2007). Crime Prevention and Active Living American Journal of Health Promotion, 21: 380-389.

Criminal Department Unit. (2005). Crime In Malaysia (Report): Royal Malaysia Police Department.

Crime concern (2002). People perception of personal security and their concern about crime on public transport: Department For Transport.

Grieco, M., Pickup, L., \& Whipp, R. (1989). Gender, transport and employment. Newcastle Upon Tyne: Athenaeum Press Ltd.

Hanlon, S., \& Johnston, I. (1985). Gender differences in work trip length: Explanation and implication. Urban Geography, 6(3), 193-219.

Howie, R. (2000). Woman and transport moving forward (Report). Scotland: The Scottish Executive Central Research Unit.

Levinson, D. (2002). Encyclopedia of crime and punishment. Sage Publication.

Nasar, J. L. \& Fisher, B. (1993). 'Hot Spots' of Fear and Crime: A Multi-Method Investigation. Journal of Environmental Psychology, 13: 187-206

Lamya Rostami Tabrizi \& Ali Madanipour (2006). Crime and the City: Domestic Burglary and the Built Environment 
in Tehran. Habitat International, 10: 932-944.

Rohana.S, Syed.H.K.S,Mashita.S,Suhana.M.(2012) Travel Safety Fear Factor Among Vulnerable Group Of Travellers: The urban Scenario, ASEAN Conference on Environmental-Behavior Studies, Bangkok Thiland,16-18 July, Elsevier Ltd. 